\title{
Erratum to: Effect of Current Electricity Simulation Supported Learning on the Conceptual Understanding of Elementary and Secondary Teachers
}

\author{
David Devraj Kumar · P. V. Thomas • \\ John D. Morris · Karen M. Tobias • \\ Mary Baker · Trudy Jermanovich
}

Published online: 23 February 2011

(C) Springer Science+Business Media, LLC 2011

\section{Erratum to: J Sci Educ Technol \\ DOI 10.1007/s10956-010-9229-4}

A revised version of Abstract is presented here to correct errors in the originally published version.

\begin{abstract}
This study examined the impact of computer simulation-supported science learning on the conceptual understanding of elementary and secondary teachers $(N=40)$. Pre/Post-tests were used to measure the teachers' concept attainment. Overall, there was a significant and large knowledge difference effect from Pre- to Posttest. Two interesting interactions were observed during the data analysis. The first was the difference between
\end{abstract}

elementary and secondary teachers. Both groups had significant gains, with large effect sizes, but the elementary teachers $\quad($ pre-mean $=3.70$, post-mean $=7.51)$ started lower and ended higher exhibiting a significantly larger gain than the secondary teachers (pre-mean $=4.96$, postmean $=6.71$ ). The second interaction was the impact of gender. Both groups showed significant gains, with large effect sizes, but females (pre-mean $=3.90$, postmean $=7.21$ ) gained significantly more than males (premean $=5.13$, post-mean $=7.01$ ). These results confirm that computer simulation supported science learning can have a positive effect on concept attainment in teachers.

The online version of the original article can be found under doi:10.1007/s10956-010-9229-4.

D. D. Kumar $(\bowtie) \cdot$ J. D. Morris

College of Education, Florida Atlantic University,

2912 College Avenue, Davie, FL 33314, USA

e-mail: david@fau.edu

\section{P. V. Thomas}

Thin Film Lab, Mar Ivanios College, Trivandrum 695015, India

K. M. Tobias

Sheridan Technical Center, 5400 Sheridan Street, Hollywood,

FL 33021, USA

M. Baker - T. Jermanovich

School Board of Broward County, 600 SE 3rd Avenue,

Fort Lauderdale, FL 33301, USA 